\title{
Journal of the American Board of Family Medicine Online Use on the Upswing
}

Readership of the Fournal of the American Board of Family Medicine ( $7 A B F M)$ online journal continued to grow in 2006. Figure 1 illustrates the number of total access events (sometimes called hits) plus the full-text HTML and PDF accesses over 12 months. New issues are published 6 times per year, and these months are marked on the figure as well. Reader use of the $7 A B F M$ online journal grew rapidly in the second half of the year, peaking at more than 117,000 access events with the publication of the final issue in November 2006.

\section{E-Mail Alerts}

Readers can sign up to receive e-mailed announcements of the contents of new issues the day they are posted online by clicking on "E-mail Alerts" in the left navigation bar at http://www.jabfm.org. E-mail alerts announcing future tables of contents and a variety of other types of alerts are also available.

\section{Top 20 JABFM Online Articles in 2006}

Table 1 presents the 20 most frequently accessed $7 A B F M$ articles in 2006. $7 A B F M$ content is open access and available back to 2003 in full-text HTML and PDF formats and in PDF format for 2001 and 2002 (http://www.jabfm.org). The article "Abnormal Uterine Bleeding: A Management Algorithm" by John Ely et al was the most read during 2006, which is remarkable given that the article was published in the final issue of the year.

Conflict of interest: The authors are editors and staff of the 7ABFM.

Corresponding author: A. Victoria Neale, $\mathrm{PhD}, \mathrm{MPH}, \mathrm{De}-$ partment of Family Medicine and Public Health Sciences, Wayne State University, Detroit, MI 48201 (E-mail: vneale@med.wayne.edu).
John Ely also had a second article in the top 20 (“Approach to Leg Edema of Unclear Etiology").

Also noteworthy is the continued strong interest in 2 articles published in 2003, one by John Astin et al ("Mind-Body Medicine: State of the Science, Implications for Practice") and the other by Dwenda Gjerdingen ("The Effectiveness of Various Postpartum Depression Treatments and the Impact of Antidepressant Drugs on Nursing Infants").

Six of the 2006 top 20 were published in 2004 . Tamara Dominguez's article, "It's Not a Spider Bite, It's Community-Acquired Methicillin-Resistant Staphylococcus aureus," was one of the first to call attention to the fact that methicillin-resistant Staphylococcus aureus (MRSA) is being misdiagnosed as spider bites. The Center for Disease Control is now alerting health care providers to this: http:// www.cdc.gov/ncidod/dhqp/ar_mrsa_ca_clinicians. html (dated February 3, 2005).

Alan Douglass also authored 2 publications in the 2006 top 20 accessed articles ("Evaluation and Treatment of Low Back Pain in Family Practice" and "Evaluation and Treatment of Posterior Neck Pain in Family Practice"). These 2 articles were published in the $7 A B F P 2004$ pain supplement.

As shown in Table 1, the list of $7 A B F M$ papers most read in 2006 also illustrates our readership's strong interest in evidence-based clinical medicine and what is sometimes called complementary and alternative medicine, in this case fish oil, yoga, and mind-body medicine.

Anne Victoria Neale, $\mathrm{PhD}, \mathrm{MPH}$ Wayne State University, Detroit, MI Marjorie A. Bowman University of Pennsylvania, Philadelphia, PA Cynthia A. Rose, MBA Wayne State University, Detroit, MI 
JABFM Online Access Events by Month, 2006

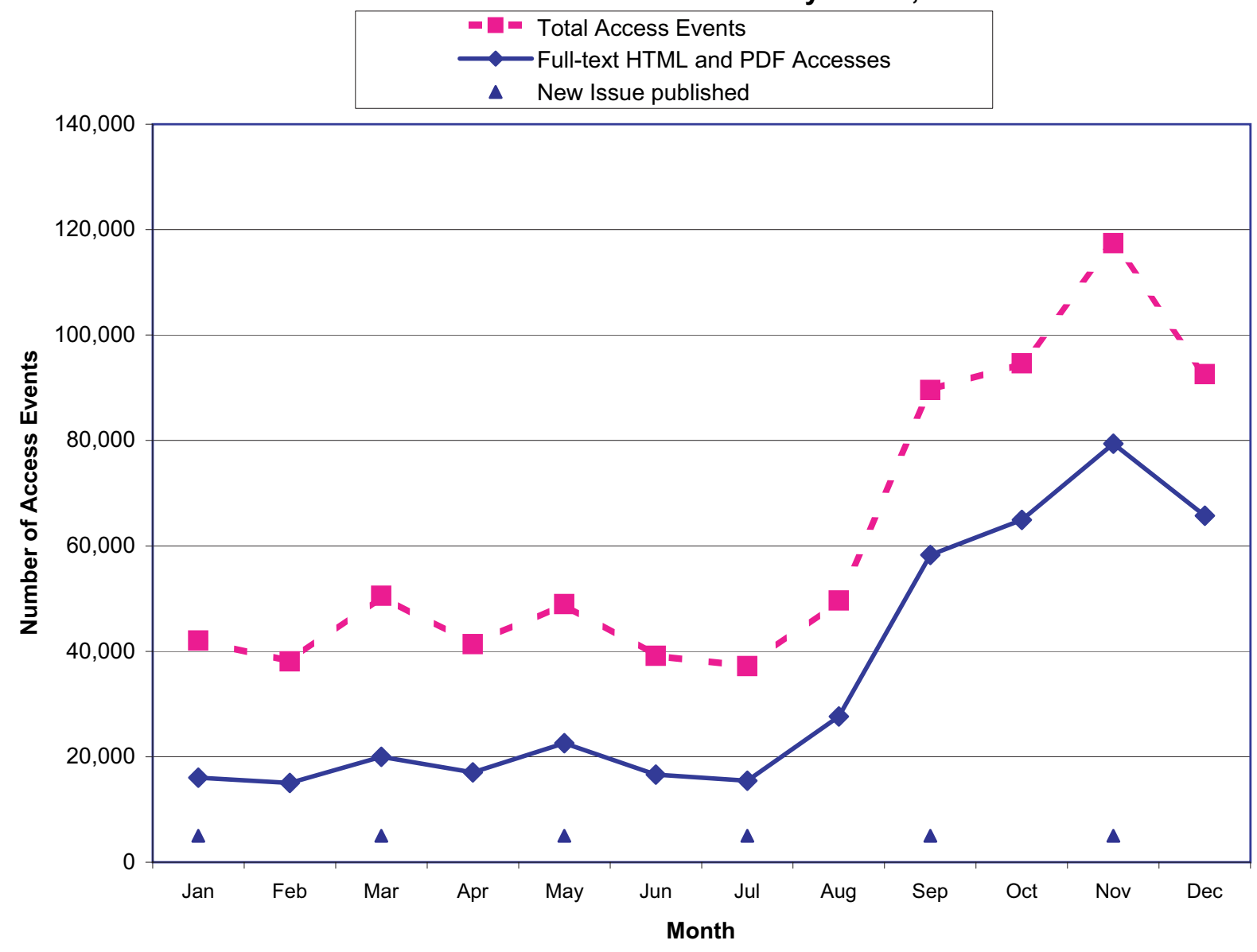

Figure 1. Data source: "Year-to-Date Usage Summary" for the JABFM, HighWire Press; produced January 6, 2007 (accessed January 9, 2007). 
1. John W. Ely, Colleen M. Kennedy, Elizabeth C. Clark, and Noelle C. Bowdler Abnormal Uterine Bleeding: A Management Algorithm 7 Am Board Fam Med, Nov-Dec 2006;19:590-602

2. Rade N. Pejic and Daniel T. Lee Hypertriglyceridemia 7 Am Board Fam Med, May-June 2006;19:310-6

3. John A. Astin, Shauna L. Shapiro, David M. Eisenberg, and Kelly L. Forys Mind-Body Medicine: State of the Science, Implications for Practice 7 Am Board Fam Pract, Mar-April 2003;16:131-47

4. Robert $\mathrm{Oh}$

Practical Applications of Fish Oil ( $\Omega-3$ Fatty Acids) in Primary Care 7 Am Board Fam Pract, Jan-Feb 2005;18:28-36

5. John W. Ely, Jerome A. Osheroff, M. Lee Chambliss, and Mark H. Ebell Approach to Leg Edema of Unclear Etiology 7 Am Board Fam Med, Mar-April 2006;19:148-60

6. Erika N. Ringdahl, Susan L. Pereira, and John E. Delzell Treatment of Primary Insomnia 7 Am Board Fam Pract, May-June 2004;17:212-9

7. Daniel E. Hall Religious Attendance: More Cost-effective Than Lipitor? 7 Am Board Fam Med, Mar-April 2006;19:103-9

8. Dwenda Gjerdingen

The Effectiveness of Various Postpartum Depression Treatments and the Impact of Antidepressant Drugs on Nursing Infants 7 Am Board Fam Pract, Sep-Oct 2003;16:372-82

9. Margaret M. Eberl, Chester H. Fox, Stephen B. Edge, Cathleen A. Carter, and Martin C. Mahoney BI-RADS Classification for Management of Abnormal Mammograms 7 Am Board Fam Med, Mar-April 2006;19:161-4

10. Anthony A. Mork, Scott M. W. Haufe, and William B. Yancey Sometimes (What Seems to Be) A Heart Attack Is (Really) A Pain In The Neck 7 Am Board Fam Pract, Jan-Feb 2004;17:74-7

11. A. John Orzano and John G. Scott Diagnosis and Treatment of Obesity in Adults: An Applied Evidence-based Review 7 Am Board Fam Pract, Sep-Oct 2004;17:359-69

12. Peter A. Rives and Alan B. Douglass Evaluation and Treatment of Low Back Pain in Family Practice 7 Am Board Fam Pract, Nov-Dec 2004;17(Suppl):23-31

13. Tamara J. Dominguez It's Not a Spider Bite, It's Community-acquired Methicillin-resistant Staphylococcus aureus 7 Am Board Fam Pract, May-June 2004;17:220-6

14. Howard S. Kirshner, José Biller, and Alfred S. Callahan Long-term Therapy to Prevent Stroke 7 Am Board Fam Pract, Nov-Dec 2005;18:528-40

15. Alan B. Douglass and Edward T. Bope Evaluation and Treatment of Posterior Neck Pain in Family Practice 7 Am Board Fam Pract, Nov-Dec 2004;17(Suppl):13-22

16. Kim E. Innes, Cheryl Bourguignon, and Ann Gill Taylor Risk Indices Associated with the Insulin Resistance Syndrome, Cardiovascular Disease, and Possible Protection with Yoga: A Systematic Review 7 Am Board Fam Pract, Nov-Dec 2005;18:491-519

17. Sarina Schrager Dietary Calcium Intake and Obesity 7 Am Board Fam Pract, May-June 2005;18:205-10

18. Cathy A. Bryant Nursing the Adopted Infant 7 Am Board Fam Med, Jul-Aug 2006;19:374-9

19. Lee T. Dresang Colposcopy: An Evidence-based Update 7 Am Board Fam Pract, Sep-Oct 2005; 18:383-92

20. M. Angelyn Bethel and Mark N. Feinglos Basal Insulin Therapy in Type 2 Diabetes 7 Am Board Fam Pract, May-June 2005;18:199-204

* The most-read rankings are recalculated at the beginning of each month. Rankings are based on hits received by articles archived on the $7 A B F M$ Web site only.

† Data source: 'The 20 Most Frequently Read Articles' for the $7 A B F M$, January 2006 through December 2006, HighWire Press; updated monthly, last on January 9, 2007 (accessed January 9, 2007). 